Tohoku J. Exp. Med., 2010, 220, 299-306

\title{
Potentiating Effect of $\beta$-Glucans on Photodynamic Therapy of Implanted Cancer Cells in Mice
}

\author{
Dalia Akramiene, ${ }^{1}$ Ceslava Aleksandraviciene, ${ }^{2}$ Grazina Grazeliene, ${ }^{2}$ \\ Rimantas Zalinkevicius, ${ }^{3}$ Kestutis Suziedelis, ${ }^{2}$ Janina Didziapetriene, ${ }^{2}$ \\ Ulf Simonsen, ${ }^{4}$ Edgaras Stankevicius ${ }^{1}$ and Egidijus Kevelaitis ${ }^{1}$
}

\author{
${ }^{1}$ Department of Physiology, Kaunas University of Medicine, Kaunas, Lithuania \\ ${ }^{2}$ Institute of Oncology, Vilnius University, Vilnius, Lithuania \\ ${ }^{3}$ Institute of Endocrinology, Kaunas University of Medicine, Kaunas, Lithuania \\ ${ }^{4}$ Department of Pharmacology, University of Aarhus, Aarhus, Denmark
}

\begin{abstract}
Photodynamic therapy (PDT) combines a drug or photosensitizer with a specific type of light to kill cancer cells. The cellular damage induced by PDT leads to activation of the DNA damage repair, which is an important factor for modulating tumor sensitivity to this treatment. $\beta$-Glucans are natural polysaccharides that bind complement receptor 3 on the effector cells, thereby activating them to kill tumor cells during PDT. The hypothesis of the present study was that adjuvant therapy with $\beta$-glucans would increase the efficacy of PDT. C57BL/6 female mice were subcutaneously implanted with Lewis lung carcinoma cells. Ten days after implantation, the mice were administered intravenously sodium porfimer $(10 \mathrm{mg} / \mathrm{kg}) 24 \mathrm{~h}$ prior to laser irradiation, with or without oral administration of $\beta$-glucan $(400 \mu \mathrm{g} / \mathrm{d} / \mathrm{mouse}, 5$ days) from either barley, baker's yeast, or marine brown algae that contains the storage glucan, laminarin. Tumor volume and necrotic area in excised tumors were measured. The expression of proliferating cell nuclear antigen (PCNA) was determined as an indicator of the activity of the DNA damage repair system. PDT in combination with each $\beta$-glucan significantly reduced tumor growth $(P<0.05, n=10)$ and expression of PCNA $(P<0.001$, $n=9)$, and increased necrosis in tumor tissues $(P<0.001, n=9)$. Furthermore, each structurally different $\beta$-glucan exerted similar potentiating effects on PDT. The present findings show that $\beta$-glucans enhance the tumor response to PDT, resulting in pronounced necrosis of PDT-treated tumors and suppression of the DNA damage repair system.
\end{abstract}

Keywords: photodynamic therapy; $\beta$-glucan; proliferating cell nuclear antigen; complement receptor 3; DNA damage repair

Tohoku J. Exp. Med., 2010, 220 (4), 299-306. 을 2010 Tohoku University Medical Press

Photodynamic therapy (PDT) combines a drug or photosensitizer with a specific type of light to kill cancer cells. In addition to producing necrosis and/or prompting apoptosis in the tumor, PDT also triggers the immune system of the host which results in damages of nutrient blood vessels to the tumor (Dougherty et al. 1998; Wilson 2002; Dolmans et al. 2003; Vrouenraets et al. 2003). Activation of the complement cascade plays an important role in the PDT-induced response and treatment outcome (Korbelik et al. 2004). Thus, blocking the receptors of the anaphylatoxins $\mathrm{C} 3 \mathrm{a}$ and C5a (Korbelik et al. 2004) or the depletion of neutrophils (Kousis et al. 2007) both significantly decrease tumor cure rates induced by PDT. In contrast, adjuvant treatment with complement-activating agents enhances the therapeutic effect of PDT (Cecic et al. 2005; Korbelik and Cooper 2007). $\beta$-Glucans induce a primed state of complement receptor type 3 (CR3, CD11b/CD18) that can trigger killing of iC3b-target cells e.g. tumor cells that are otherwise resistant to cytotoxicity (Vetvicka 1996; Xia 1999; Ross 2000). Therefore, administration of $\beta$-glucan with the photosensitizer during PDT would be expected to enhance killing of iC3b-opsonized tumor cells.

$\beta$-Glucans are polysaccharides in the cell wall of yeast, fungi and pathogenic bacteria. Dectin- 1 is considered the main receptor for $\beta$-glucans (Brown et al. 2002), and in cooperation with tool-like receptor 2 (TLR2) plays a role both in the activation of macrophages in response fungal and mycobacterial infections and participates in absorption of $\beta$-glucans from the gastrointestinal tract (Yadav and Schorey 2006; Suram 2006; Reid et al. 2009).

$\beta$-Glucans are also produced by a variety of plants, such as oat, barley and seaweed, and depending on the

Received October 16, 2009; revision accepted for publication March 11, 2010. doi:10.1620/tjem.220.299

Correspondence: Dalia Akramiene, Department of Physiology, Kaunas University of Medicine, A. Mickeviciaus 9, LT-44307 Kaunas,

Lithuania.

e-mail: dalia.akramiene@takas.lt 
source the $\beta$-glucans are structurally different (Ishibashi et al. 2001; Brown and Gordon 2003; Mantovani et al. 2007). Oat and barley $\beta$-glucans are linear polymers with $(1 \rightarrow 3)-\beta$ and $(1 \rightarrow 4)-\beta$-linkages in their backbone, but no branches; mushroom and fungal $\beta$-glucans have the $(1 \rightarrow 3)-\beta$-linkage in the backbone and $(1 \rightarrow 6)-\beta$-linked branches (Cheung and Modak 2002; Brown and Gordon 2003; Liu et al. 2009). It was previously thought that $(1 \rightarrow 3),(1 \rightarrow 6)-\beta$ linkage was required for the antitumor effect of $\beta$-glucans (Bohn and BeMiller 1995), but later it was shown that $(1 \rightarrow 3),(1 \rightarrow 4)$ $\beta$-glucan binds CR3, activates antibody-dependent cellular cytotoxicity in vitro, and acts in synergy with monoclonal antibodies in vivo (Cheung and Modak 2002). We recently found that high molecular weight, unbranched $(1 \rightarrow 3),(1 \rightarrow$ 4)- $\beta$-glucan from barley suppresses growth of PDT-treated Lewis lung carcinoma tumors (Akramiene et al. 2009), but others reported that also schizophyllan, a branched high molecular weight $(1 \rightarrow 3),(1 \rightarrow 6)-\beta$-glucan, potentiates PDT (Krosl and Korbelik 1994). These studies agree with recent observations that apart from the presence of the $(1 \rightarrow 3),(1 \rightarrow$ $6)-\beta$ linkage, the size and complexity of $\beta$-glucan are important for the interaction with human cells (Liu et al. 2009). Therefore, $\beta$-glucan from different sources may affect tumor growth differently.

In addition to cell killing, PDT activates the cellular DNA damage repair system, which could be an important factor that modulates tumor sensitivity to this treatment. Proliferating cell nuclear antigen (PCNA) has a triple function in life and death of the cells. It is an essential component of the DNA replication machinery, functioning as the accessory protein for DNA polymerase delta required for chromosomal DNA synthesis, and DNA polymerase epsilon required for DNA recombination and repair of DNA damage. Absence or a low level of functional PCNA may drive cells into apoptosis (Kelman 1997). Overexpression of PCNA is used as a monitor of tumor cell cycle time and is the most frequent change found in tumor cells relative to controls, particularly in tumor cells showing enhanced resistance to radiotherapy (Paunesku et al. 2001). PCNA reflects both cellular proliferation and DNA damage repair. Therefore, we have chosen it for the evaluation of DNA damage repair system during PDT.

The hypothesis of the present study was that $\beta$-glucan in combination with PDT will produce more effective killing of PDT-treated tumor cells. To address the hypothesis we investigated the effect of orally administered $\beta$-glucan isolated from either barley or baker's yeast or marine brown algae, which contains the storage $\beta$-glucan, laminarin. The $\beta$-glucan was administered alone and in combination with PDT in mice bearing Lewis lung tumors. Tumor growth and expression of proliferating cell nuclear antigen expression was evaluated, and necrosis in tumor tissue was measured to estimate the efficiency of the treatments.

\section{Materials and Methods}

\section{Animals and tumor model}

C57BL/6 female mice (obtained from Immunology Institute, Vilnius, Lithuania) at 8-10 weeks of age and 19-22 g body weight were used. Mice were injected subcutaneously with $0.2 \mathrm{ml}$ of Lewis lung carcinoma (LLC) cells $\left(2 \times 10^{6}\right.$ cells $)$ in the right groin. Ten days after implantation, tumors reached $400-600 \mathrm{~mm}^{3}$ volume and the mice were then subjected to treatment. Tumor volume was determined by measuring the tumor diameter with vernier calipers and calculating the volume according to the following formula: tumor volume $=\mathrm{L} \times$ $\mathrm{W} \times \mathrm{H} \times \pi / 6$ ( $\mathrm{L}$ is length, $\mathrm{W}$ is width and $\mathrm{H}$ is height of the tumor).

All animal procedures were performed in accordance with the guidelines established by the Lithuanian Animal Care Committee, which approved the study (No. 0179).

\section{Photosensitizer}

Photofrin (porfimer sodium, a kind gift from Axan Pharma Inc., Mont-Saint-Hilaire, Quebec, Canada) was dissolved in $0.9 \%$ sodium chloride solution and used at a concentration of $10 \mathrm{mg} / \mathrm{kg}$. It was injected intravenously into tumor-bearing mice, except for those in the control group, $24 \mathrm{~h}$ before the tumors were exposed to laser irradiation.

\section{Laser irradiation}

Tumors $\left(400-600 \mathrm{~mm}^{3}\right)$ in the PDT-treated groups were irradiated with light from a diode laser (Institute of Oncology, Vilnius University, Vilnius, Lithuania) with a $630 \pm 2 \mathrm{~nm}$ wavelength and a $160 \mathrm{~mW} / \mathrm{cm}^{2}$ fluence rate for $15 \mathrm{~min}$, to achieve a dose of $200 \mathrm{~J} / \mathrm{cm}^{2}$. During laser treatment individual animals were anesthetized.

\section{Glucans}

Three types of $\beta$-glucans were used in the study. $\beta$-Glucan from baker's yeast (powder, Sigma-Aldrich, Steinheim, Germany) is $(1 \rightarrow$ $3),(1 \rightarrow 6)-\beta$-glucan with a high number of $\beta$-( $1 \rightarrow 6)$-linked branches. Laminarin, a storage polysaccharide of the marine brown algae $L$. digitata (powder, Sigma-Aldrich, Steinheim, Germany), is a linear $\beta$-(1 $\rightarrow 3)$-linked glucan with occasional $\beta$ - $(1 \rightarrow 6)$-linked branches $[\beta(1$ $\rightarrow 3$ ): $\beta(1 \rightarrow 6$ ) ratio of 3:1]. $\beta$-Glucan from barley (powder, SigmaAldrich, Steinheim, Germany) is a large molecular weight, unbranched $(1 \rightarrow 3),(1 \rightarrow 4)-\beta$-glucan. All $\beta$-glucans were dissolved in phosphate-buffered saline (PBS) and administered orally at a dose of $400 \mu \mathrm{g} /$ mouse (volume $0.2 \mathrm{ml}$ ) every day up to 5 days, starting on the same day as Photofrin administration.

\section{Immunohistochemical analysis}

Every day, starting on the day of Photofrin injection (Fig. 1c), 3 mice from each group were sacrificed, and LLC-derived tumors were excised. Immediately following excision, the tumors were placed in formalin solution for 1 week. Then 3 sections from the each tumor were cut for immunohistochemical analysis.

Immunohistochemical reactions were carried out using a ChemMate EnVision (DAKO A/S, Glostrup, Denmark) technique. Tissue sections were incubated for $10 \mathrm{~min}$ in $0.3 \%$ hydrogen peroxide solution in absolute methanol to block endogenous peroxidase. After microwave retrieval of antigens in $10 \mathrm{mmol} / \mathrm{L}(\mathrm{pH} 6.0)$ citrate buffer and washes in PBS, all sections were treated with $1 \%$ normal horse serum in PBS and then incubated for 30 min with mAbs PC10 against PCNA. After washes in PBS, dextran coupled with peroxidase and 


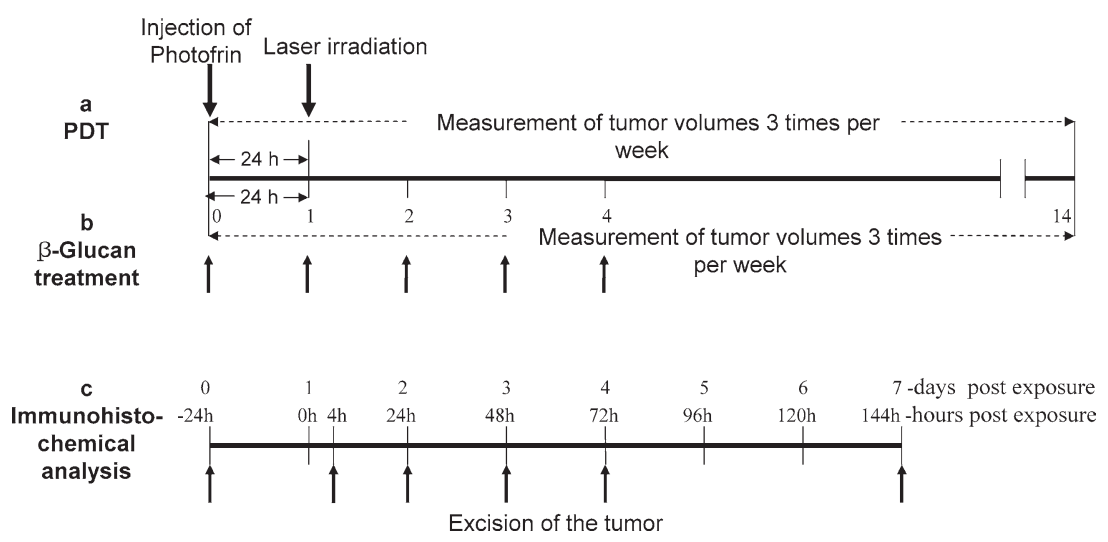

Fig. 1. Experimental design.

Shown are the schedules for PDT (a), $\beta$-glucan treatment (b) and immunohistochemical analysis (c).

goat secondary antibody against rabbit and mouse immunoglobulins (ChemMate EnVision detection kit, DAKO A/S, Glostrup, Denmark) were applied. Between incubations the sections were washed 3 times in PBS. Chromogenic development was obtained using 3,3-diaminobensidine (DAB) and hydrogen peroxide (ChemMate EnVision detection kit; DAKO A/S, Glostrup, Denmark). Negative controls were performed, omitting primary antibodies. Finally, sections were counterstained with hematoxylin, cleared, mounted and examined at $400 \times$ magnification. Immunohistochemical expression was visualized by the product of the chromogenic reaction (oxidized DAB precipitate) staining the cells. Color of the oxidized DAB precipitate varies in intensity (from light brown to dark brown) and indicates positive expression. For evaluation of PCNA scores, 1,000 tumor cells were counted from throughout the entirety of each section. The necrotic areas in all tissue samples were analyzed using the fields of vision method (Taylor and Cote 1994).

\section{Experimental design}

The experiment with each type of $\beta$-glucans was performed separately. Mice were coded and randomized into 4 groups during each experiment ( $n=10$ each group): Control group, mice did not receive any treatment; PDT group, Photofrin was injected intravenously $24 \mathrm{~h}$ prior to laser irradiation (Fig. 1a); $\beta$-glucan group, $\beta$-glucan, either from barley, baker's yeast, or laminarin, was administered orally at a dose of $400 \mu \mathrm{g}$ /mouse daily up to 5 days (Fig. 1b); PDT + $\beta$-glucan group, Photofrin was injected intravenously $24 \mathrm{~h}$ prior to laser irradiation and $\beta$-glucan, from either barley, baker's yeast, or marine brown algae which contain the storage $\beta$-glucan, laminarin, was administered orally at a dose of $400 \mu \mathrm{g} /$ mouse daily up to 5 days starting on the same day as Photofrin injection.

\section{Data analysis}

GraphPad Prism 3.0 software was used for the statistical analysis. Tumor response results were statistically analyzed using 2-way ANOVA. Data are given as group means \pm standard deviation. Average tumor size and PCNA expression level over time between two groups was tested for significant difference using Fisher's $F$ test. The medians of necrotic area between two groups were compared by Mann-Whitney test. Statistical differences were considered significant when $P<0.05$.

\section{Results}

Tumor growth dynamic

To evaluate the treatment effect in LLC-bearing mice, tumor volume was measured every second day (3 times per week) starting on the day treatment began till the end of the experiment. The pilot experiments revealed the absence of anti-tumor activity of laser irradiation without Photofrin or vice versa (data not shown).

Tumor volumes in all treated groups were significantly less $(P<0.05)$ than those in the control group (Fig. 2a, b, c.). As shown in Fig. 2a, LLC tumor volumes were lowest in the group in which mice were treated with PDT in combination with laminarin. Tumor volume differed significantly $(P<0.05)$ compared with tumors in the control group, but the difference was not significant between tumor volume size of mice treated with PDT alone or by laminarin alone $(P>0.05)$.

Mean tumor volume in all treated groups was significantly lower $(P<0.05)$ than that in the control group (Fig. $2 b)$. Both treatment regiments, administration of PDT alone and $\beta$-glucan from barley alone, have shown a significant efficacy $(P<0.001)$ in tumor growth suppression in LLC tumor-bearing mice as compared with untreated mice. However, tumor volume after the treatment with $\beta$-glucan from barley alone was less in comparison to treatment with PDT alone, but the difference was not significant $(P>0.05)$. The most effective tumor growth suppression was achieved in mice treated with combination of PDT and $\beta$-glucan from barley, and the difference was significant $(P<0.05)$ as compared with PDT alone.

The most pronounced effect was achieved with the treatment by PDT in combination with $\beta$-glucan from baker's yeast (Fig. 2c). Tumor volumes in this group were significantly lower than in the control $(P<0.01)$ and the PDT $(P<0.05)$ groups. $\beta$-Glucan from baker's yeast showed better antitumor effect than $\operatorname{did} \beta$-glucan from $L$. digitata. 
a

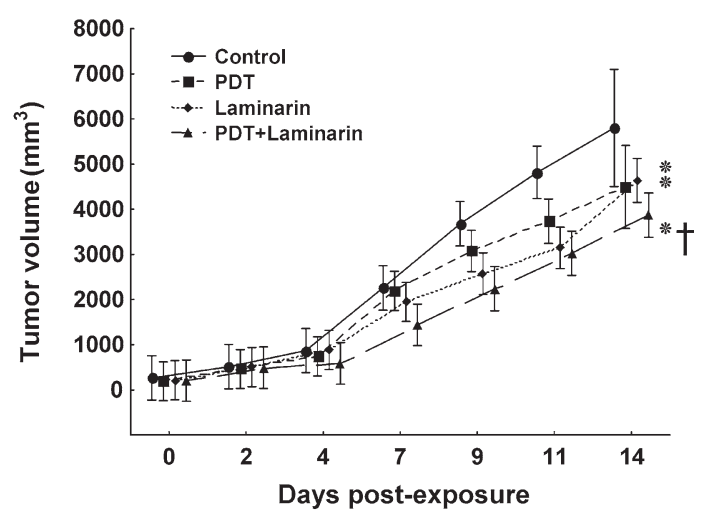

b

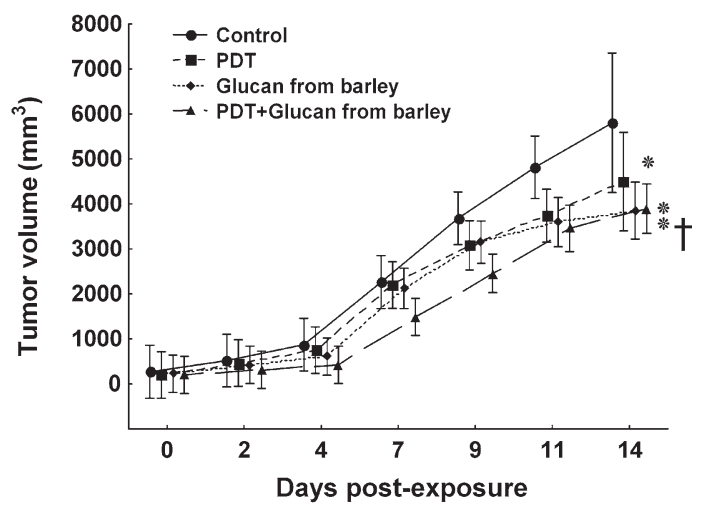

C

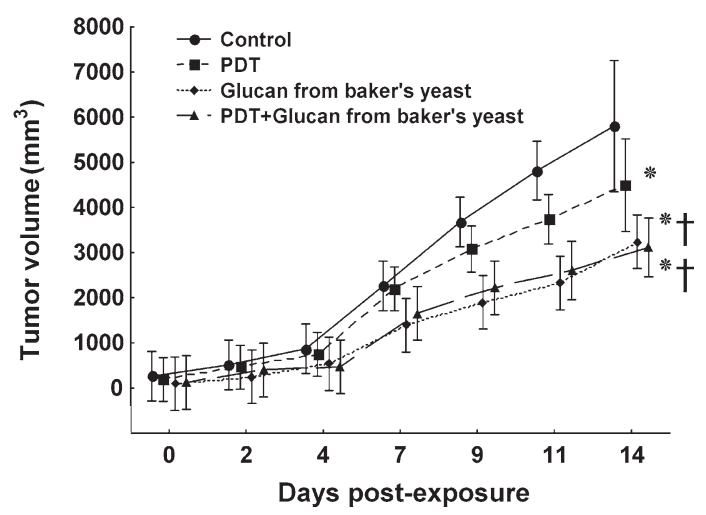

Fig. 2. Growth dynamics of LLC tumors.

The curves show changes in tumor volume in nontreated mice (Control); in mice treated by PDT (Photofrin intravenous injection followed by laser irradiation $24 \mathrm{~h}$ later); or treated with $\beta$-glucan either from L. digitata, laminarin(a), from barley (b), or from baker's yeast (c), which was administered orally at a dose of $400 \mu \mathrm{g} /$ mouse daily up to 5 days starting on the same day as Photofrin injection; or treated by combination of above mentioned method (PDT+ $\beta$-Glucan): Photofrin intravenous injection followed by laser irradiation $24 \mathrm{~h}$ later in combination with $\beta$-glucan, which was administered orally at a dose of $400 \mu \mathrm{g} /$ mouse daily up to 5 days starting on the same day as Photofrin injection. Points represents means \pm s.D.; $* P<0.001$ vs. control; ${ }^{\dagger} P<0.001$ vs. PDT; Fisher's test. a

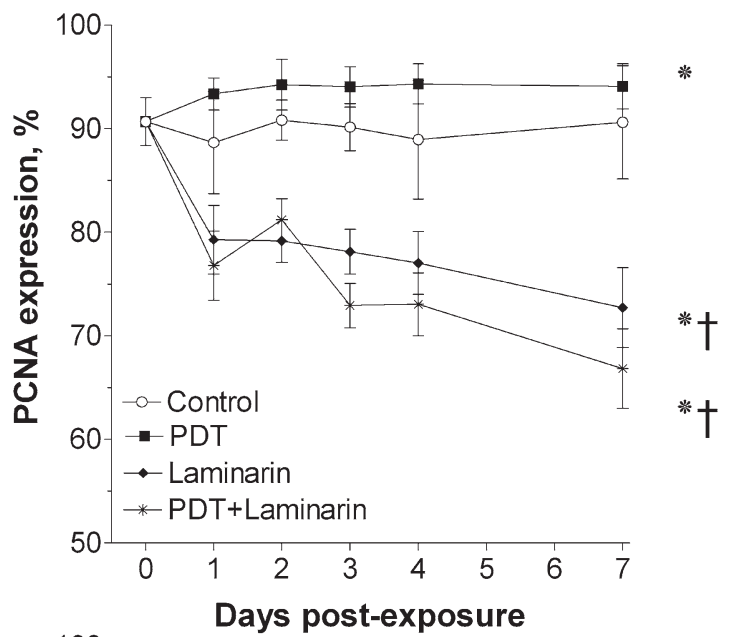

b

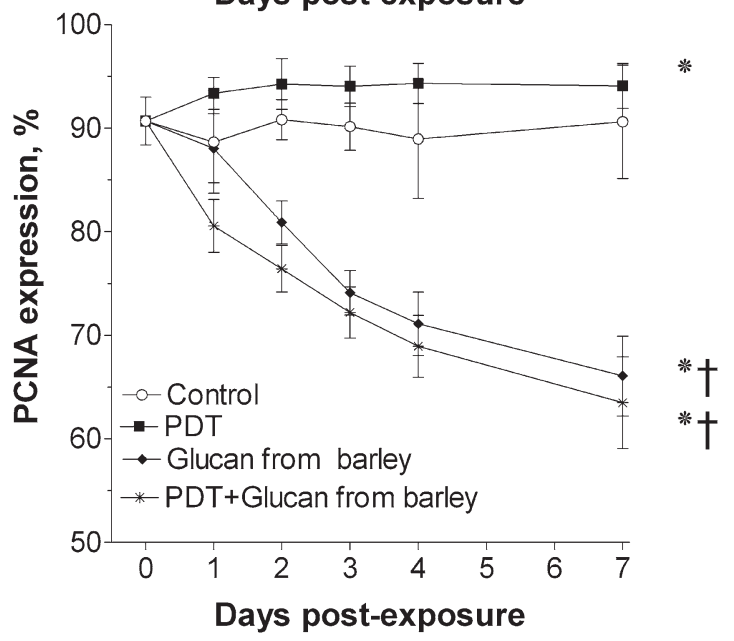

C

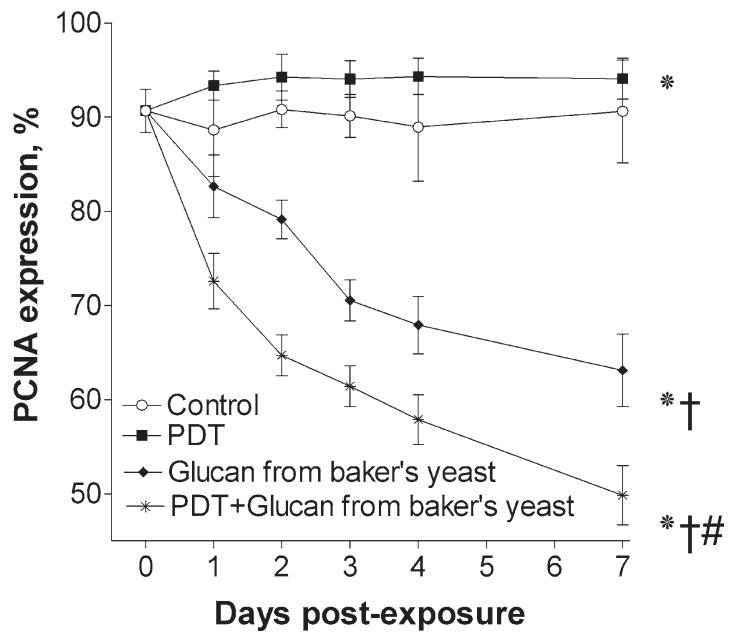

Fig. 3. PCNA expression in LLC tumors. PCNA expression level detected by immunohystochemistry in the tumors of mice treated by PDT or $\beta$-glucan either from $L$. digitata, laminarin(a), from barley (b), or from baker's yeast (c) alone, or in combination of these as described in Fig 1. Tumors of nontreated mice served as control. The points are means \pm S.D. from 3 tumors $(3$ sections of each tumor). $* P<0.001$ vs. control; ${ }^{\dagger} P<0.001$ vs. PDT $;{ }^{\#} P<$ 0.001 vs. $\beta$-glucan alone; Fisher's test. 


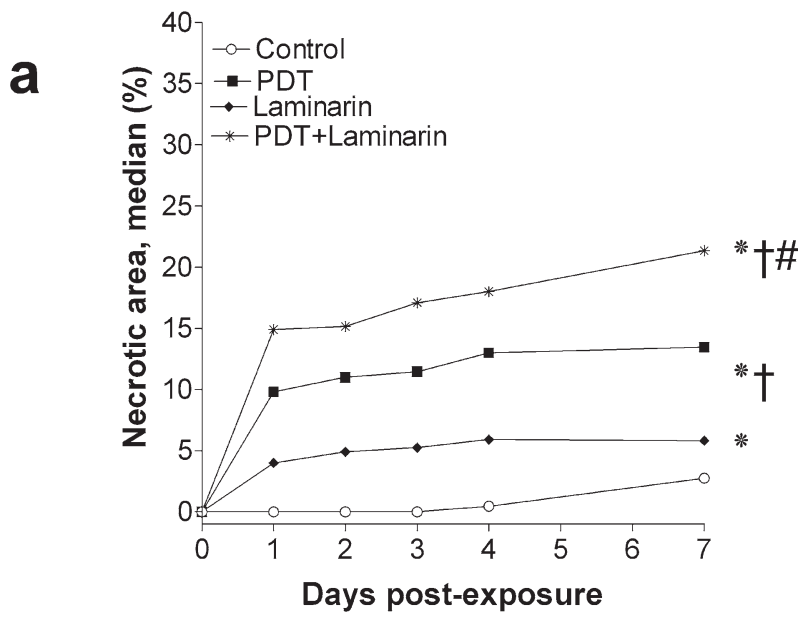

PCNA expression and necrosis in tumor tissue

The results of immunohistochemical staining show that PCNA expression in LLC tumors increased significantly after PDT treatment $(P<0.001)$ starting on the same day as laser irradiation (Fig. 3a, b, c). Necrosis was already observed in LLC tumors treated with PDT on the same day after the laser irradiation (Fig. 4a, b, c).

Both, combination treatment and treatment with $\beta$-glucan from barley significantly decreased PCNA expression in LLC tumors $(P<0.001)$ compared with nontreated tumors (Fig. 3b). Mostly PCNA expression decreased in tumors treated with PDT in combination with $\beta$-glucan from barley, but not significantly $(P>0.05)$ compare with tumors treated with $\beta$-glucan from barley alone. The largest necrotic area was detected in tumors treated with PDT in combination with $\beta$-glucan from barley (Fig. 4b). Despite decreased PCNA expression in tumors treated with $\beta$-glucan from barley alone, only single necrotic areas were detected in the tumors. But larger necrotic areas were seen in tumors treated with PDT compared with nontreated tumors and tumors treated with $\beta$-glucan from barley alone $(P<0.001)$, even though the highest PCNA expression was detected in these tumors.

As shown in Fig. 3a, PCNA expression significantly decreased in tumors, treated with laminarin alone or by PDT and laminarin $(P<0.01)$ in comparison to nontreated tumors or those treated with PDT alone. No difference in PCNA expression was observed between PDT with the laminarin combination group and the laminarin alone group. A slight, but not significant $(P>0.05)$ decrease in PCNA expression in the group with combined treatment was seen starting on day 4 post-treatment. However the area of necrosis in tumors treated with PDT in combination with laminarin is significantly $(P>0.001)$ higher compared with PDT alone (Fig. 4a). Only a few necrotic areas were detected in tumors treated with laminarin alone.

Both, combination treatment and treatment with $\beta$-glucan from baker's yeast decreased PCNA expression in LLC tumors significantly $(P<0.001)$ compare with nontreated tumors (Fig. 3c), but the lowest PCNA expression level was achieved with PDT combined with $\beta$-glucan from baker's yeast $(P<0.001)$. The largest necrotic area was detected in tumors treated with PDT in combination with $\beta$-glucan from baker's yeast (Fig. 4c). Despite decreased PCNA expression in tumors treated with $\beta$-glucan from baker's yeast alone, only single necrotic areas were detected in the tumors. In contrast, despite having the highest PCNA expression compared with other treatment groups and the control group, LLC tumors treated with PDT had larger necrotic areas compared with nontreated tumors and tumors treated with $\beta$-glucan from baker's yeast alone $(P<0.001)$.

The lowest PCNA expression $(P<0.001)$ was detected in LLC tumors treated with PDT combined with $\beta$-glucan from baker's yeast compared with tumors treated with PDT in combination with either $\beta$-glucan from barley or laminarin (Fig. 3). No significant difference was observed between 
combinations of PDT with $\beta$-glucan from barley or with laminarin $(P>0.05)$. A similar necrotic area was detected in tumors of mice treated with PDT and laminarin or $\beta$-glucan from barley. PDT in combination with $\beta$-glucan from baker's yeast produced significantly more pronounced necrosis in tumor tissue.

In LLC tumors treated with $\beta$-glucan from barley or laminarin or with $\beta$-glucan from baker's yeast alone, PCNA expression was also significantly lower $(P<0.001)$ compared with nontreated tumors (Fig. 3). As shown here, the lowest PCNA expression in tumors treated with $\beta$-glucans alone was achieved after treatment with $\beta$-glucan from baker's yeast starting on day 3 post-exposure to treatment, but the difference was not significant $(P>0.05)$ compared to tumors treated with $\beta$-glucan from barley.

\section{Discussion}

This study provides evidence that $\beta$-glucans enhance complement receptor type 3 -dependent cytotoxicity and suppress tumor proliferation when administered with PDT.

PDT induces cancer tissue damage, which initiate inflammatory and immune responses. The complement system plays a pivotal role in these responses and its activity contributes to the cure rate of tumors treated with PDT (Korbelik et al. 2004; Nowis et al. 2005). The kinetics of systemic and PDT-treated tumor-localized activation of the complement system have been described by Cecic et al. (2005). They showed that the level of complement 3 , the key protein in the complement cascade, in PDT-treated tumors peaks $3 \mathrm{~h}$ after phototherapy and remains highly activated until $24 \mathrm{~h}$ post-PDT, and the potential for complement activation via alternative pathway persists to $72 \mathrm{~h}$, finally returning to the pretreatment level at 7 days postPDT. During this period of time, PDT-treated tumor cells are opsonized by iC $3 b$ fragments and cytotoxic degranulation of the effector cells can be induced after the priming of CR3 by $\beta$-glucan, and this period of time is essential for the action of $\beta$-glucan. Therefore, $\beta$-glucans were administered $24 \mathrm{~h}$ before the laser irradiation in our study. The rationale for this timing stems from a previous study, which reported that a minimum of 3 days after oral administration is needed for macrophages to degrade the large molecules of digested $\beta$-glucan into smaller active fragments, which primes CR3 on the effector cells (Hong et al. 2004). However, others have reported (Rice et al. 2005) that a high concentration of $\beta$-glucan appears already $3 \mathrm{~h}$ after oral administration. Orally and intravenously administered $\beta$-glucan functions by a similar mechanism (Hong et al. 2004). Intravenous $\beta$-glucan is delivered directly to the CR3 on circulating granulocytes. Orally administered high molecular weight $\beta-1,3$ glucans, such as glucan from baker's yeast and barley (Hong et al. 2004), or small molecular weight $\beta$-1,3 glucans, such as laminarin (Rice et al. 2005), go through an intermediate step in which they are taken up by gastrointestinal macrophages and shuttled to reticuloendothelial tissue and bone marrow. Once there, macrophages degrade large molecules of $\beta$-glucan into smaller biologically active fragments ( $\mathrm{Li}$ et al. 2006). The active fragments are slowly released from the macrophages, bind to mature bone marrow neutrophil or NK cell CR3, and prime these cells for targeted killing through the 3-Syk-phosphatidylinositol 3-kinase signaling pathway (Li et al. 2006).

Treatment with a combination of PDT and $\beta$-glucan in the current study produced significantly larger necrotic area in tumor tissue than PDT alone (Fig. 3) and this support the findings of other researches, that CR3-dependent phagocytosis and cytotoxic degranulation requires dual ligation of both the lectin-like domain and the inserted (I) domain of the CD11b subunit of CR3 (CD11b/CD18, Mac-1) (Vetvicka 1996; Xia 1999; Ross 2000). Without $\beta$-glucan, iC3b-opsonized tumor cells are resistant to killing, because they, like all human and mammalian cells, lack $\beta$-glucan in their membrane. Microbes can activate the lectin domain on CR3, leading to effective phagocytosis and cytotoxic degranulation (Cheung and Modak 2002; Gelderman et al. 2004; Liu et al. 2009). Therefore, these processes can be induced by coadministration of $\beta$-glucan together with the agents, which cause opsonization of tumor cells by iC $3 b$ fragment. The ability of $\beta$-glucan to enhance the activity of antitumor monoclonal antibodies (mAbs) also requires that they activate complement and deposit $\mathrm{iC} 3 \mathrm{~b}$ on tumor cells for recognition by CR3 on granulocytes and NK cells (Cheung and Modak 2002; Hong et al. 2003). It has been demonstrated that $\beta$-glucan from both barley (Cheung and Modak 2002; Modak et al. 2005) and yeast (Yan et al. 1999; Hong et al. 2003, 2004; Li et al. 2006, 2007) has synergistic effects when used with anticancer mAbs in various tumor models. The mechanism of action has been explained in several studies (Hong et al. 2003, 2004; Li et al. 2006).

It has been reported that PDT results in DNA lesions such as single-strand breaks and DNA degradation as well as in chromosome aberrations (Evans et al. 1997; Oleinick and Evans 1998). DNA damage induces several cellular responses including DNA repair and the triggering of apoptotic pathways (Niida and Nakanishi 2006). Lower expression of PCNA after the treatment with $\beta$-glucan reflects decrease in cellular proliferation. However, it also indicates lower potential for DNA damage repair in these cells. The absence of the activation of PCNA expression in tumors treated with combination of PDT and $\beta$-glucan indicates both the low proliferation and low DNA damage repair. This is consistent with an observation that combined treatment results in the best photodynamic effect. On the other hand, treatment with PDT alone results in a significantly higher PCNA level (Fig. 3), which can be related to an activation of DNA damage repair, that prevent necrosis induction in tumor tissue. Therefore, the treatment with $\beta$-glucan in combination with PDT could positively modulate the photodynamic effect by inhibition of the DNA damage repair system, which activated by PDT alone.

Our data show that the most pronounced effect was achieved when PDT was combined with $(1 \rightarrow 3),(1 \rightarrow 6)$ - 
$\beta$-glucan from baker's yeast. Therefore, it supports an idea, which was noted by Mueller et al. (2000) that branching frequency may enhance the affinity of the polymer for the glucan receptor, and a polymer with greater molecular weight exhibits higher binding affinity. In addition, larger molecular weight $\beta$-glucans are absorbed more rapidly from the intestinal tract (Rice et al. 2005), which can cause higher concentration of the substance at the tumor site.

Current data show that all $\beta$-glucans, when used alone, suppress LLC tumor growth and proliferation (Fig. 2 and 3). The antitumor activity of $\beta$-glucans is known and has been reported in several studies with fungal $(1 \rightarrow 3),(1 \rightarrow 6)-\beta$-glucan, such as shizophylan, lentinam (Ooi and Liu 2000; Zhang et al. 2005), $(1 \rightarrow 3),(1 \rightarrow 6)-\beta$-glucan from yeast (Kiho et al. 1998). It can be explained that after implantation of tumor cells naturally elicited antitumor antibodies most probably occur, and they function similarly to exogenous antitumor mAbs by coating tumor cells with iC $3 \mathrm{~b}$ fragments (Hong et al. 2004). Moreover, $\beta$-glucan converts the nonprotective Th2-type response, which has been reported as dominant in the course of cancer, to a protective Th1-type response that favors cytotoxic T lymphocytes activity (Baran et al. 2007). Therefore, it can result in more effective tumor elimination and produce necrosis of tumor tissue when is given alone to treat LLC tumors.

An anti-angiogenesis activity of $\beta$-glucan can not be excluded. Polysaccharopeptide (PSP), which has $\beta$-glucan as the main polysaccharide component and is isolated from the edible mushroom Coriolus versicolor, was tested in the mouse sarcoma-S180 tumor model (Ho et al. 2004). Immunostaining of tumor tissues with antibody against the endothelial cell marker (factor VIII) demonstrated a positive correlation in that both the vascular density and tumor weight were lower in mice treated with PSP. The total amount of new vessel production was reduced, and the basic tumor type-specific vascular architecture was retained. However, the expression of vascular endothelial cell growth factor in these tumors was suppressed. Angiogenesis is crucial to tumor growth and metastasis, and interruption of this process is one of the therapeutic interventions against tumor proliferation. This may explain why wherefore PCNA expression decreased also in tumors, treated by $\beta$-glucans alone. In the current study we observed that tumor tissue from mice treated with $\beta$-glucan alone or in combination with PDT was less infiltrated by erythrocytes compared with nontreated tissue or tissue treated with PDT alone. We postulate that it could be due to suppression of tumor angiogenesis. Thus, anti-angiogenesis can be one of the pathways through which $\beta$-glucans mediate antitumor activity.

In conclusion, the present study showed, that unbranched high molecular weight $(1 \rightarrow 3),(1 \rightarrow 4)-\beta$-glucan from barley, branched high molecular weight $(1 \rightarrow 3),(1 \rightarrow 6)$ $\beta$-glucan from baker's yeast and low molecular weight $(1 \rightarrow 3),(1 \rightarrow 6)-\beta$-glucan from the seaweed $L$. digitata can all enhance the efficacy of photodynamic treatment. Coadministration of $\beta$-glucans enhance the tumor response to photo- dynamic therapy, resulting more pronounced necrosis of PDT-treated tumors and suppression of the DNA damage repair system, which is activated by PDT.

\section{Acknowledgments}

We thank the Lithuanian Science and Studies Foundation for the financial support granted for the research project No. T77/08.

Prof. Egidijus Kevelaitis passed away during preparation of the manuscript.

\section{References}

Akramiene, D., Grazeliene, G., Didziapetriene, J. \& Kevelaitis, E. (2009) Treatment of Lewis lung carcinoma by photodynamic therapy and glucan from barley. Medicina (Kaunas), 45, 480-485.

Baran, J., Allendorf, D.J., Hong, F. \& Ross, G.D. (2007) Oral $\beta$-glucan adjuvant therapy converts nonprotective Th2 response to protective Th1 cell-mediated immune response in mammary tumor-bearing mice. Folia Histochem. Cytobiol., 45, 107-114

Bohn, J.A. \& BeMiller, J.N. (1995) (1-3)- $\beta$-D-glucans as biological response modifiers: a review of structure-functional activity relationships. Carbohydr. Polym., 28, 3-14.

Brown, G.D. \& Gordon, S. (2003) Fungal $\beta$-glucans and mammalian immunity. Immunity, 19, 311-315.

Brown, G.D., Tailor, P.R., Reid, D.M., Willment, J.A., Williams, D.L., Martinez-Pomares, L., Wong, S.Y. \& Gordon, S. (2002) Dectin-1 is a major beta-glucan receptor on macrophages. $J$. Exp. Med., 196, 407-412.

Cecic, I., Serrano, K., Gyongyossy-Issa, M. \& Korbelik, M. (2005) Characteristics of complement activation in mice bearing Lewis lung carcinomas treated by photodynamic therapy. Cancer Lett., 225, 215-223.

Cheung, N.K.V. \& Modak, S. (2002) Oral $(1 \rightarrow 3)(1 \rightarrow 4) \beta$-D-glucan synergizes with antiganglioside GD2 monoclonal antibody 3F8 in the therapy of neuroblastoma. Clin. Cancer Res., 8 , 1217-1223.

Dolmans, D.E.J.G.J., Fukumura, D. \& Jain, R.K. (2003) Photodynamic therapy for cancer. Nat. Rev. Cancer, 3, 380-387.

Dougherty, T.J., Gomer, C.J., Henderson, B.W., Jori, G., Kessel, D., Korbelik, M., Moan, J. \& Peng, Q. (1998) Photodynamic therapy. J. Natl. Cancer Inst., 90, 889-905.

Evans, H.H., Horng, M.F., Ricanati, M., Deahl, J.T. \& Oleinick, N.L. (1997) Mutagenicity of photodynamic therapy as compared to UVC and ionizing radiation in human and murine lymphoblast cell lines. Photochem. Photobiol., 66, 690-696.

Gelderman, K.A., Tomlinson, S., Ross, G.D. \& Gorter, A. (2004) Complement function in $\mathrm{mAb}$-mediated cancer immunotherapy. Trends Immunol., 25, 158-164.

Ho, J.C.K., Konerding, M.A., Gaumann, A., Groth, M. \& Liu, W.K. (2004) Fungal polysaccharopeptide inhibits tumor angiogenesis and tumor growth in mice. Life Sci., 75, 1343-1356.

Hong, F., Hansen, R.D., Yan, J., Allendorf, D.J., Baran, J.T., Ostroff, G.R. \& Ross, G.D. (2003) $\beta$-Glucan functions as an adjuvant for monoclonal antibody immunotherapy by recruiting tumoricidal granulocytes as killer cells. Cancer Res., 63 , 9023-9031.

Hong, F., Yan, J., Baran, J.T., Allendorf, D.J., Hansen, R.D., Ostroff, G.R., Xing, P.X., Cheung, N-K.V. \& Ross, G.D. (2004) Mechanism by which orally administered glucans enhance the tumoricidal activity of antitumor monoclonal antibodies in murine tumor models. J. Immunol., 173, 797-806.

Ishibashi, K., Miura, N.N., Adachi, Y., Ohno, N. \& Yadomae, T. (2001) Relationship between solubility of grifolan, a fungal $1,3-\beta$-D-glucan, and production of tumor necrosis factor by macrophages in vitro. Biosci. Biotechnol. Biochem., 65, 
1993-2000.

Kelman, Z. (1997) PCNA structure, functions and interactions. Oncogene, 14, 629-640.

Kiho, T., Matsushita, S., Usui, S. \& Ukai, S. (1998) Biological activities of (1-3)- $\beta$-glucan with reducing glucose side chains. Biosci. Biotechnol. Biochem., 62, 570-572.

Korbelik, M. \& Cooper, P.D. (2007) Potentiation of photodynamic therapy of cancer by complement: the effect of $\gamma$-inulin. $B r . J$. Cancer, 96, 67-72.

Korbelik, M., Sun, J., Cesic, I. \& Serrano, K. (2004) Adjuvant treatment for complement activation increases the effectiveness of photodynamic therapy of solid tumors. Photoch. Photobio. Sci., 3, 812-816.

Kousis, P.C., Henderson, B.W., Maier, P.G. \& Gollnick, S.O. (2007) Photodynamic therapy enhancement of antitumor immunity is regulated by neutrophils. Cancer Res., 67, 10501-10510.

Krosl, G. \& Korbelik, M. (1994) Potentiation of photodynamic therapy by immunotherapy: the effect of schizophyllan (SPG). Cancer Lett., 84, 43-49.

Li, B., Allendorf, D.J., Hansen, R., Marroquin, J., Cramer, D.E., Harris C.I. \& Yan, J. (2007) Combined yeast $\beta$-glucan and antitumor monoclonal antibody therapy requires $\mathrm{C} 5 \mathrm{a}$-mediated neutrophil chemotaxis via regulation of decay-accelerating factor CD55. Cancer Res., 67, 7421-7430.

Li, B., Allendorf, D.J., Hansen, R., Marroquin, J., Ding, C., Cramer, D.E. \& Yan, J. (2006) Yast $\beta$-glucan amplifies phagocyte killing of iCR3b-opsonized tumor cells via complement receptor 3-Syk-phosphatidylinositol 3-kinase pathway. $J$. Immunol., 177, 1661-1669.

Liu, J., Gunn, L., Hansen, R. \& Yan, J. (2009) Combined yeastderived $\beta$-glucan with anti-tumor monoclonal antibody for cancer immunotherapy. Exp. Mol. Pathol., 86, 208-214.

Mantovani, M.S., Marilanda, F.B., Angeli, J.P.F., Oliveira, R.J., Silva, A.F. \& Ribeiro, L.R. (2007) $\beta$-Glucans in promoting health: prevention against mutation and cancer. Mutat. Res., 658, 154-161.

Modak, S., Koehne, G., Vickers, A., O’Reilly, R.J. \& Cheung, N.K. (2005) Rituximab therapy of lymphoma is enhanced by orally administered $(1 \rightarrow 3),(1 \rightarrow 4)$-D-beta-glucan. Leuk. Res., 29, 679-683.

Mueller, A., Raptis, J., Rice, P.J., Kalbfleisch, H.J., Stout, R.D., Ensley, E.H., Browder, W. \& Williams, D.L. (2000) The influence of glucan polymer structure and solution conformation on binding to $(1 \rightarrow 3)-\beta$-D-glucan receptors in a human monocytelike cell line. Glycobiology, 10, 339-346.

Niida, H. \& Nakanishi, M. (2006) DNA damage checkpoints in mammals. Mutagenesis, 21, 3-9.

Nowis, D., Makowski, M., Stoklosa, T., Legat, M., Issat, T. \& Golab, J. (2005) Direct tumor damage mechanisms of photodynamic therapy. Acta Biochim. Pol., 52, 339-352.

Oleinick, N.L. \& Evans, H.H. (1998) The phothobiology of photodynamic therapy: cellular tagets and mechanisms. Radiat. Res., 150, 146-156.
Ooi, V.E.C. \& Liu, F. (2000) Immunomodulation and anti-cancer activity of polysaccharide-proteins complexes. Curr. Med. Chem., 7, 715-729.

Paunesku, T., Mittal, S., Proctic, M., Oryhon, J., Korolev, S.V., Joachimiak A., Woloschak, G.E. (2001) Proliferating cell nuclear antigen (PCNA) ringmaster of the genome. Int. J. Radiat. Biol., 77, 1007-1021.

Reid, D.M., Gow, N.A.R. \& Brown, G.D. (2009) Pattern recognition: recent insights from Dectin-1. Curr. Opin. Immunol., 21, 30-37.

Rice, P.J., Adams, E.L., Ozment-Skelton, T., Gonzales, A.J., Goldman, M.P., Lockhart, B.E., Barker, L.A., Breuel, K.F., DePonti, W.K., Kalbfleisch, J.H., Ensley, H.E., Brown, G.D., Gordon, S. \& Williams, D.L. (2005) Oral delivery and gastrointestinal absorption of soluble glucans stimulate increased resistance to infectious challenge. J. Pharmacol. Exp. Ther., 314, 1079-1086.

Ross, G. (2000) Regulation of the adhesion versus cytotoxic functions of the Mac-1/CR3/ $\alpha \mathrm{M} \beta 2$-integrin glycoprotein. Crit. Rev. Immunol., 20, 197-222.

Suram, S., Brown, G.D., Ghosh, M., Gordon, S., Loper, R., Taylor, P.R., Akira, S., Uematsu, S., Williams, D.L. \& Leslie, C.C. (2006) Regulation of cytosolic phospholipase A2 activation and cyclooxygenase 2 expression in macrophages by the betaglucan receptor. J. Biol. Chem., 281, 5506-5514.

Taylor, C. \& Cote, R.J. (1994) Immunomicroscopy: A Diagnostic Tool of the Surgical Pathologist. 2nd ed., WB Saunders, Phila.

Vetvicka, V. (1996) Soluble $\beta$-glucan polysaccharide binding to the lectin site of neutrophil or natural killer cell complement receptor type $3(\mathrm{CD} 11 \mathrm{~b} / \mathrm{CD} 18)$ generates a primed state of the receptor capable of mediating cytotoxicity of $\mathrm{iC} 3 \mathrm{~b}$-opsonized target cells. J. Clin. Invest., 98, 50-61.

Vrouenraets, M.B., Visser G.W.M., Snow G.B. \& van Dongen, G.A.M.S. (2003) Basic principles, applications in oncology and improved selectivity of photodynamic therapy. Anticancer Res., 23, 505-522.

Wilson, B.C. (2002) Photodynamic therapy for cancer: principles. Can. J. Gastroenterol., 16, 393-396.

Xia, Y. (1999) The $\beta$-glucan-binding lectin site of mouse CR3 $(\mathrm{CD} 11 \mathrm{~b} / \mathrm{CD} 18)$ and its function in generating a primed state of the receptor that mediates cytotoxic activation in response to iC3b-opsonized target cells. J. Immunol., 162, 2281-2290.

Yadav, M. \& Schorey, J.S. (2006) The beta-glucan receptor dectin1 functions together with TLR2 to mediate macrophage activation by mycobacteria. Blood, 108, 3168-3175.

Yan, J., Vetvicka, V., Xia, Y., Coxon, A., Carroll, M.C., Mayadas, T.N. \& Ross, G.D. (1999) Beta-glucan, a "specific" biologic response modifier that uses antibodies to target tumors for cytotoxic recognition by leukocyte complement receptor type 3 (CD11b/CD18). J. Immunol., 163, 3045-3052.

Zhang, L., Xuelian, L., Xu, X. \& Zeng, F. (2005) Correlation between antitumoral activity, molecular weight, and conformation of lentinam. Carbohydr. Res., 340, 1515-1521. 